\title{
Education Teaching Quality in Local Colleges and Universities Liu Honglin ${ }^{1 a}$ Zhi Fengsheng ${ }^{2 b}$ \\ 1Huaiyin Institute of Continuing Education, Huaian, Jiangsu, China \\ 2Huaiyin Institute of Audit Huai'an, Jiangsu, China \\ a email: 870270890@qq.com \\ b email :2575621866@qq.com \\ Corresponding author: Liu Honglin
}

Key words: Local adult higher education, Teaching Quality, promotion, research

\begin{abstract}
The quality of teaching in adult education is not high, there are problems such as inaccurate training orientation, disregard of talent training programs and social needs, which affects the social recognition of adult higher education. The organizer of Adult Education must strengthen the leadership of Adult Education, improve the teaching technology of Adult Education, construct the curriculum system of Adult Education, optimize the organizational structure of Adult Education, innovate the organizational culture of teaching, and strive to improve the teaching quality of Adult Education. Only in this way can we truly cultivate the education for local economic development Talents task, for the local community to make its due contribution to the harmonious construction and development.
\end{abstract}

\section{地方高校成教教学质量提升探索}

\author{
刘洪林 ${ }^{1 \mathrm{a}}$, 支风生 ${ }^{2 \mathrm{~b}}$ \\ 1 淮阴工学院继续教育学院, 淮安, 江苏, 中国 \\ 2 淮阴工学院审计处淮安, 江苏, 中国 \\ a email: 870270890@qq.com \\ b email :2575621866@qq.com
}

通讯作者：刘洪林

关键词: 地方成人高等教育 教学质量 提升 研究

摘要: 成教教学质量不高, 存在培养定位不准确, 人才培养方案与社会需求脱节等问题, 影 响了社会对成人高等教育的认可。成教举办者必须加强成教教学领导, 改善成教教学技术水 平, 构建成教人才培养课程体系, 优化成教组织结构, 创新教学组织文化, 努力提升成教教 学质量, 如此, 才能真正担当起为地方解决经济发展培养人才的重任, 为地方社会和谐建设 和发展做出应有的贡献。

\section{1. 引言}

随着高等教育招生生源的逐年萎缩，成教的生源更是呈明显的负增长，地方高校成教赖 以生存的教学质量提升成为成教办学亟待解决的紧迫问题, 各地方高校成教部门都在想方设 法积极探索成教教学质量提升的路径和方法, 不断改进教学, 但效果不甚明显, 成功的案例 不多。那么, 究竟是什么原因导致成教教学质量难以提升的? 有哪些因素障碍成教教学质量 
的提高? 应当采取什么样的措施, 来提升地方高校成教教学质量? 这是我们成教人无法回避 的问题。

\section{2、地方高校成教教学质量状况及分析}

地方高校与普通高校一样, 承载着高等教育的基本功能, 成人高等教育肩负着为地方解 决、社会发展培养人才的重任, 是普通高等教育的有益补充。教学质量不提高, 那一切功能 和重任都无从说起。教学质量的构成包括教学资源建设、教学课程设置人才培养理念等教学 战略; 还包括教学水平、教学质量控制、课程实施等教学技术; 也包括教学管理、教师激励 等教学领导和教学制度等。每个构成要素都可能对教学质量产生一定的影响。这都要具体分 析，从地方高校成教工作中寻找问题和答案。

\section{1 成教教学质量现状}

教师基本能够按照教学大纲的要求进行教学, 教学中大多数教师都能够采用多媒体等现 代化教学手段, 教师对学生所提出的问题都能及时给予解决; 但教师和学生对教学质量认识 水平总体上不是很高, 具体表现在教学设施不能满足教学需要, 教学管理方法滞后, 教学信 息传递不通畅, 教师入职培训机会较少, 社会教学资源缺乏有效利用, 教与学的互动不良, 从生产生活中带来的问题不多, 所学知识与社会经济发展需要结合的不是很紧密, 社会对成 教教学质量的认可度较低等。

\section{2 成教教学质量存在的问题}

1、培养定位不准确。地方高校成人高等教育是高等教育的重要组成部分，成人高等教育的人 才培养目标是为地方经济发展提供建设人才。成教的培养目标定位是比较准确的, 但在将成 人高等教育教学目标转化为学校成教培养目标时, 难以精确理解和科学定位。对于如何培养, 怎样培养比较科学, 并没有真正关注。

2、成教的生源质量普遍较差。成教的学生大多数是通过普通高考淘汰下来的, 一般成绩都比 较差, 组织纪律散漫, 有一部分学员甚至连初中都没有读完, 这部分学生的学习兴趣较低, 学习能力较差。自由散漫现象普遍, 这也直接导致教师在上课时常常需要拿出大部分的时间 来维持课堂秩序。

3、成教师资来源单一, 质量不高。成教需要更多的高素质 “双师型” 教师, 这是提高教学质 量的前题和基础。然而, 由于普通高校的扩招, 本身师资就紧张, 根本抽不出又红又专的教 师给成教上课, 再加上成教举办单位对成教的轻视, 成教教师只能满足基本的教学需要, 根 本谈不上教学质量的提升。大部分教师为本校教师, 外涉教师较少, 成教尚需要加大摄入社 会优质教学资源力度。

4、人才培养方案不能与时俱进，与社会需求脱节。

5、对学生的评价多为闭卷，缺少多元评价体系的建立。

6、相当部分教师对成教的教学管理有不同看法, 抱怨居多, 成教教学管理方式和手段需要改 进。

7、相当一部分教师少有机会参加校外教学培训, 成教教师教学培训有较大的努力空间。

\section{3 成教教学质量存在问题的原因及分析}

成教所聘教师多数是本校的边缘教师，这部分教师的科研能力不是很强，一般都希望通 过日常的课堂教学来体现自身的价值; 如果学校外聘教师参与教学, 不仅会挤占有限的课时, 还会减少校内教师课时收入, 更会影响校内教师在教学中的地位, 所以校内教师不希望外聘 教师参与教学; 因此校内成教教师的教学理念需要提升。同时, 成教学生由于自身文化底子 比较薄弱, 自卑心重缺乏自学和发现问题的信心，学生的自信心需要提高。

教师在教学过程中, 处于引领地位, 在课堂上是绝对的领导, 是培养学生遨游知识海洋 
的教练; 所以在教学质量改进中, 教师良好教学信念、对教学角色的认知、对专业的认知、 现代化教学手段的运用、注重课程间联系、科研促进教学、对学生学习指导、教学方法改进、 研究等方面构建的教师教学学术提高, 将有效提升教学质量。

教学制度的人本化和教师对教学质量理解度越高, 则教学质量改进越容易推进。教师更 希望根据实际需要组成教学团队, 在组织中突破科层制限制。学校对教学管理服务、目标管 理、对教学培训服务、教学分权等教学领导行为将对教学质量形成具有非常正向的引领作用, 影响着成人高等教育教学质量的形成与改进; 教师主动追求新知的意识, 还有待于进一步提 高。

\section{3. 地方高校成教教学质量提升路径}

\section{1 改善成教教学技术水平，促进成教教学质量的提升}

教学技术水平是成教教师教学水平、教学质量保障与改进的集中体现, 是其促进教学质 量提升的有效途径。成教教学的实践性特点, 要求教师的教学学术应是学科内容知识、生产 实践知识与教学法知识的系统整合, 需要即时地和社会实践相结合, 能够促进地方经济发展。 所以, 成教举办者应注重发展教师个体实践、反思与同伴交流和评价相结合的发展模式, 重 构有利于教学学术生成的教学评价、保障制度, 促进教师树立教师职业取向, 营造教学学术 自由, 着力转变教师单纯依属学科的理念, 不断地将理论性成果转化为现实生产力。

\section{2 构建成教人才培养课程体系, 保证成教教学质量的提升}

课程是教学的载体, 课程传递的内容、价值将内化为学生的个体特征。成人高等教育主 要是为地方社会经济发展提供人才; 所以, 成教课程选择应当符合地方经济社会组织中所需 要的知识与技能, 以社会经济发展需要为取向, 按照社会经济发展的要求设置并选择学科课 程包括复合课程体系，在满足社会需求与满足学生个体需要之间保持恰当的平衡。

\section{3 加强成教教学领导, 引领成教教学质量的提升}

成教教学活动中存在明显的教学领导与不同学科之间教师交流很少、征求教师和学生之 意见不多、教学激励不足和教学培训关注度少等问题。所以, 教学领导需要持有明确而崇高 的价值观, 将价值观具体化、目标化, 融入到教学的愿景中, 主动寻求变革, 把 “教学质量 不断改进” 作为教学规范; 教学管理更多地强调与员工打交道, 以一种直觉和移情的方式与 员工进行交往, 回避单独行为突破科层体制的限制, 营造激励性的教学环境以及交换或交易 合约, 和对教师的教学改革行为进行补偿的氛围, 来赋予教师追求更多专业知识的动力; 解 放教师的教学权力, 促进教学团队自我学习, 换取师生对教学质量改进的道德承诺和舒心乐 意的服从; 强化教师教学变革管理, 充分发挥教师教学选择的自由权, 为教师提供更多的参 与教学讨论、教学决策和创造学校教学文化中来，以积极鼓励与支持教学改革与创新。

\section{4 优化成教组织结构, 支持成教教学质量提升}

成人教学组织结构是教学领导用以实现大学教学目标的一种有效手段, 是成教组织一切 活动严格按照制度运行, 教师按照教学要求和条例实施教学行为, 开展教学活动的保证; 教 学管理者需要根据组织情境, 合理地使用集权与分权有机结合耦合组织结构, 以使教师们更 为有效率地开展教学工作。因此, 成教管理者必须走出 “象牙塔”, 与环境接触, 与企 (事) 业单位建立广泛的联系。应当根据自身组织规模、所处外部环境中社会岗位需求变化、同质 性专业的设置、地区发展战略导向等适时地进行内部结构调整, 确定开放的、动态的、团队 式的以教学运行为导向的组织系统结构, 以有利于学科专业的发展。 


\section{5 创新教学组织文化, 加速成教教学质量提升}

任何变革如果没有触及组织文化的改变, 将不可能有好的结果。教师是教学运行的参与 者, 他们塑造教学运行环境, 也会被教学实践环境所改变。创新教学组织文化, 有利于加速 成教教学质量提升。有远见的教学领导要创新教学组织文化发展的动力, 对教师教学关注, 对学生成长的关系、组织学习、鼓励创新、重视结果和系统进行思考, 诊断和启动教学组织 文化变革, 有效且有利地推进教学质量改进工作, 将变革阻力降低到最小的且可控的范围内。 教学质量改进的进程, 将是教学组织氛围最显著的标志, 成教教学质量改进中, 应突破旧有 的教学理念、教学行为和教学管理模式, 努力关注大学组织中教职员工共享的教育教学价值 观、假设、信念、工作礼仪以及态度和规范的教学文化, 塑造有利于创新与变革的组织文化, 形成促进全体教师进行教学质量改进的良好组织氛围。致力于调和某一质量文化下的各种亚 文化的差异, 并努力将亚文化力量转向成教组织文化的内涵建设上, 预期经济社会发展变化, 迅速研究并提出新的教学改革方案, 帮助教学组织获取更大的竞争力, 尽快实现教学质量改 进的目标。

\section{References:}

[1] Liu Honglin. Problems and Countermeasures in the Construction of Adult Education Textbooks [J]. Journal of Wuhan Institute of Metallurgical Administration, 2016,26 (04)

[2] Liu Honglin. Based on social recognition adult teaching materials quality control system construction [J]. Higher Education Journal, 2016 (23)

[3] Liu Honglin. Adult Higher Education Management Based on the Perspective of Local Economic Development [J]. Continuing Education Research, 2015 (07)

[4] [4] Zhang Qiu-seok. Development of university teaching quality assessment mechanism [D]. Central China Normal University. 2016 (04)

[5] Yang Caixia; Zou Xiaodong. Student-Centered Guarantee of Teaching Quality in Higher Education Institutions: Concept Construction and Improvement Strategy [J] .Educational Research and Development, 2015 (02)

[6] Wang Weizheng Sun Fang Li Yu. Exploration of teaching quality management under the connotation of university development [J]. China Higher Education Research 2015 (04) 